\title{
Filling the Technical Gap between Standard Endoscopic Mucosal Resection and Full Endoscopic Submucosal Dissection for 20-35 mm Sized Colorectal Neoplasms
}

\author{
Sung Noh Hong \\ Department of Medicine, Samsung Medical Center, Sungkyunkwan University School of Medicine, Seoul, Korea
}

See "Endoscopic Mucosal Resection with Circumferential Mucosal Incision for Colorectal Neoplasms: Comparison with Endoscopic Submucosal Dissection and between Two Endoscopists with Different Experiences" by Dong-Hoon Yang, Min-Seob Kwak, Sang Hyoung Park, et al., on page 379-387.

Endoscopic submucosal dissection (ESD) is an innovative endoscopic technique used for excision of superficial gastrointestinal neoplasms. Compared to endoscopic mucosal resection (EMR), ESD has the potential to achieve a high rate of en bloc resection, regardless of tumor size, leading to precise histological evaluation of specimen margins and a lower recurrence rate observed at long-term follow-up. ${ }^{1}$ Although ESD was first utilized for resection of superficial gastric neoplasms, ${ }^{2,3}$ it is popularly being used as a standard treatment modality for management of superficial colorectal neoplasms $20 \mathrm{~mm}$ in diameter for lesions where en bloc resection using standard EMR is difficult. ${ }^{4}$ However, limitations to its use in routine clinical practice include technical difficulties, significant time required to learn the technique, long procedure time, and increased risks of associated complications, such as postoperative bleeding and perforation. ${ }^{5}$ Reportedly, the colorectal ESD-induced perforation rate is as high as $1.4 \%$ to $20.4 \%$ owing to the anatomy of the large intestine with its narrow lumen, thin walls, tortuous structure, and redundancy. ${ }^{6}$

Received: July 4, 2017 Accepted: July 10, 2017

Correspondence: Sung Noh Hong

Department of Medicine, Samsung Medical Center, Sungkyunkwan University School of Medicine, 81 Irwon-ro, Gangnam-gu, Seoul 06351, Korea

Tel: +82-2-3410-3409, Fax: +82-2-3410-6983, E-mail: gisnhong@gmail.com

(c) This is an Open Access article distributed under the terms of the Creative Commons Attribution Non-Commercial License (http://creativecommons.org/ licenses/by-nc/3.0) which permits unrestricted non-commercial use, distribution, and reproduction in any medium, provided the original work is properly cited.
Standard EMR is considered a more reliable, easier, safer, and quicker technique compared to a full ESD.

Colorectal ESD is not very popular and is rarely performed in countries other than Korea and Japan due to lack of universal acceptance. Given that the primary goal of endoscopic resection for colorectal neoplasms is to prevent spread of colorectal cancer and reduce cancer-related mortality, en bloc resection is preferred, when feasible, to maximize the accuracy of histological assessment and to reduce the risk of local recurrence ensuing from incomplete excision that might occur with use of piecemeal methods. ${ }^{7}$ Therefore, simplification of the ESD technique or improvements in EMR through use of modified techniques and development of newer devices is warranted because curative en bloc resection is often the best management for large superficial colorectal tumors and early invasive colorectal cancers. Several modified EMR and simplified ESD techniques have been proposed to fill the gap between standard EMR and full ESD techniques.

The scratch-stick-method proposed by Nomura et al. ${ }^{8}$ is one of the first advanced EMR techniques to be introduced. Using the tip of the snare, the electrocautery makes a scratch in the normal mucosa oral to the lesion. After the tip of the snare is fixed into the scratch to stabilize the polypectomy snare, an EMR is performed. The complete resection rate achieved using this scratch-stick-method for colorectal tumors $\geq 20$ $\mathrm{mm}$ was observed to be higher than that of standard EMR $(65 \%$ vs. $35 \%){ }^{8}$ No severe complications and no recurrence at 
the site of EMR were noticed in the group, which underwent EMR using the scratch-stick-method. Toyonaga et al. have proposed EMR with a small incision (EMR with SI) method as an advanced EMR technique and a hybrid (simplified) ESD method as a simplified ESD technique. ${ }^{9}$ EMR with SI technique is performed as follows: After submucosal injection, a 1-2 mm sized small mucosal incision is created using the tip of the snare in the normal mucosa oral to the site of the lesion. The snare is then used with its tip pushed lightly into the incision. Because the tip of the snare is fixed, appropriate snaring can be achieved by sliding the tip of the sheath vertically or horizontally. ${ }^{9}$ A hybrid ESD technique is performed as follows: A circumferential incision is made, and submucosal dissection is carried out to a certain degree after which snaring is performed. ${ }^{9}$ In their initial report Toyonaga et al. found the mean resected size of specimens obtained was $22.5 \mathrm{~mm}$ in the EMR with SI group, $26 \mathrm{~mm}$ in the hybrid ESD group, and $41 \mathrm{~mm}$ in the full ESD group. ${ }^{9}$ Procedure time, en bloc resection rate, and perforation rate was 19 minutes, $83.3 \%$, and $0.0 \%$ in the EMR with SI group, respectively; 27 minutes, $90.9 \%$, and $4.5 \%$ in the hybrid ESD group, respectively, and 60 minutes, $98.9 \%$, and $1.5 \%$ in the full ESD group, respectively. ${ }^{9}$ The complication rate noted in the EMR with SI group was very low but was found to be higher compared to the ESD group. ${ }^{9}$ Byeon et al. report outcomes of an ESD with snaring method (ESD-S). ${ }^{10}$ Unlike with the hybrid ESD technique, with the ESD-S, an ESD is initially performed and the snare is used only during the final step of resection. A retrospective analysis to determine treatment outcomes in cases of nonpedunculated colorectal neoplasms $\geq 15 \mathrm{~mm}$, it was found that the en bloc resection rate of the ESD-S group was slightly lower than that of the ESD group (64\% vs. $87 \%$ ). Additionally, the procedure time was shorter than that observed with the ESD group ( $49 \pm 35$ minutes vs. $35 \pm 24$ minutes, $p<0.01$ ). The perforation rate observed in the ESD-S group was lower than that observed in the ESD group ( $7 \%$ vs. $3 \%, p=0.24) .^{10}$

In this issue of Clinical Endoscopy, Yang et al. have proposed EMR with a circumferential mucosal incision (CMIEMR) method, ${ }^{7}$ which is performed as follows: After submucosal injection, a circumferential incision is made along the peripheral rim of the lesion with a $2-5 \mathrm{~mm}$ lateral safety margin. Unlike in a full ESD, ESD-S, and hybrid ESD, little or no submucosal dissection is performed after creating a groove around the mass following the circumferential incision. Yang et al. have analyzed the outcomes of CMI-EMR $(n=34)$ and size-matched ESD $(n=102)$, which were performed by a Korean endoscopist for colorectal epithelial lesions measuring 20-35 $\mathrm{mm}$ in size. ${ }^{7}$ The resection time noted in the CMI-EMR group was significantly shorter than that observed in the ESD group (12.7 \pm 7.0 minutes vs. $45.6 \pm 30.1$ minutes, $p<0.001)$. The en bloc resection rate of the CMIEMR group was $94.1 \%$, which was comparable with that of the ESD group (100\%, $p=0.061)$. There was no significant difference noted between the groups in terms of postoperative bleeding ( $2.9 \%$ vs. $1.0 \%, p=0.439)$ and perforation rate $(5.9 \%$ vs. $2.9 \%, p=0.599)$. CMI-EMR for colorectal neoplasms measuring $20-35 \mathrm{~mm}$ in size was shown to be associated with an excellent en bloc resection rate and offers an advantage of a shorter procedure time compared to an ESD.

Moreover, Yang et al. analyzed procedural parameters of CMI-EMRs performed by an American ESD novice $(n=30)$ compared to those performed by a Korean expert endoscopist. $^{7}$ There were no differences between the CMI-EMRs performed by the American and Korean endoscopist in terms of en bloc resection and complication rates. The American endoscopist having limited experience with colorectal ESD performed the CMI-EMR procedure safely and achieved an en bloc resection rate comparable to that achieved by the Korean ESD expert, suggesting that the CMI-EMR does not require a very high level of expertise to achieve appropriate clinical outcomes with CMI-EMR.

Theoretically, full ESD is considered the most appropriate technique for en bloc resection of large superficial tumors and early submucosal invasive cancers that develop in the colorectum. However, ESD has not been widely promoted and popularized as an effective treatment modality for such lesions, possibly because compared to EMR techniques, it is technically more difficult, takes longer, and is associated with a higher risk of complications. Modifications to the standard EMR and full ESD technique have been proposed to overcome these drawbacks. The CMI-EMR method is one such modification to fill the gap between a standard EMR and full ESD technique.

\section{Conflicts of Interest}

The author has no financial conflicts of interest.

\section{REFERENCES}

1. Repici A, Hassan C, De Paula Pessoa D, et al. Efficacy and safety of endoscopic submucosal dissection for colorectal neoplasia: a systematic review. Endoscopy 2012;44:137-150.

2. Lee EJ, Lee JB, Lee SH, Youk EG. Endoscopic treatment of large colorectal tumors: comparison of endoscopic mucosal resection, endoscopic mucosal resection-precutting, and endoscopic submucosal dissection. Surg Endosc 2012;26:2220-2230.

3. Tanaka S, Oka S, Kaneko I, et al. Endoscopic submucosal dissection for colorectal neoplasia: possibility of standardization. Gastrointest Endosc 2007;66:100-107.

4. Kiriyama S, Saito Y, Yamamoto S, et al. Comparison of endoscopic submucosal dissection with laparoscopic-assisted colorectal surgery for early-stage colorectal cancer: a retrospective analysis. Endoscopy 
2012;44:1024-1030.

5. Swanström LL. Treatment of early colorectal cancers: too many choices? Endoscopy 2012;44:991-992.

6. Hong SN, Byeon JS, Lee BI, et al. Prediction model and risk score for perforation in patients undergoing colorectal endoscopic submucosal dissection. Gastrointest Endosc 2016;84:98-108.

7. Yang DH, Kwak MS, Park SH, et al. Endoscopic mucosal resection with circumferential mucosal incision for colorectal neoplasms: comparison with endoscopic submucosal dissection and between two endoscopists with different experiences. Clin Endosc 2017;50:379-387.
8. Nomura M, Fujita N, Matsunaga A, et al. Scratch-stick-method for endoscopic mucosal resection of colorectal tumors. Gastroenterological endoscopy 2001;43:1821-1827.

9. Toyonaga T, Man-I M, Morita Y, et al. The new resources of treatment for early stage colorectal tumors: EMR with small incision and simplified endoscopic submucosal dissection. Dig Endosc 2009;21 Suppl 1:S31-S37.

10. Byeon JS, Yang DH, Kim KJ, et al. Endoscopic submucosal dissection with or without snaring for colorectal neoplasms. Gastrointest Endosc 2011;74:1075-1083. 